\title{
Biomimetic modelling
}

\author{
Julian F. V. Vincent \\ Department of Mechanical Engineering, University of Bath, Bath BA2 7AY, UK (j.f.v.vincent@bath.ac.uk)
}

Biomimetics is seen as a path from biology to engineering. The only path from engineering to biology in current use is the application of engineering concepts and models to biological systems. However, there is another pathway: the verification of biological mechanisms by manufacture, leading to an iterative process between biology and engineering in which the new understanding that the engineering implementation of a biological system can bring is fed back into biology, allowing a more complete and certain understanding and the possibility of further revelations for application in engineering. This is a pathway as yet unformalized, and one that offers the possibility that engineers can also be scientists.

Keywords: biomimetics; toughness; sensing; wood; technology transfer

\section{INTRODUCTION}

I am a biologist in a department of engineering. This engenders some interesting tensions. Shortly after I took up the job, one of the lecturers said, 'You're an engineer now, you're not a scientist any more'. This made me realize that engineers have to design things that work and that are safe. If they understand how things work, so much the better, it may mean that they have more design space available to them. But as long as it works, is saleable, gets to the market place and makes a profit that is all that really matters. This is not so far from the ethos of evolution: survival is the only criterion of success.

I have brought together a collection of mechanisms from biology which has been taken through what one might call a biomimetic pathway into some sort of engineering environment. There are few biomimetic mechanisms or processes that work well in engineering because it is early days for biomimetics as a method for technology transfer. The transactions between biology and engineering are based on energy; in biology we have optimization processes partitioning the energy between the various functions of the organism, such as locomotion, reproduction, repair and growth. In engineering there is again an array of optimizations so that the energy (cash) available is partitioned out among design, construction, management, maintenance, etc. In both cases, keeping to the evolutionary theme, we have a general principle-the survival of the cheapest (Vincent 2002). This holds true for engineering as well as biology. In nature, we compete for food in general; and a good engineer is someone who can do a job for half the price that another engineer would charge. Minimal use of energy is, therefore, a really important driver when moving from biology to engineering. We can therefore take ideas from biology not just as mechanisms or materials, but also the implementation of those mechanisms.

$\overline{\text { One contribution of } 20 \text { to a Theme Issue 'Modelling in biomechanics'. }}$

\section{JOINTING MECHANISMS}

I have defined biomimetics as the abstraction of good design from nature. The only successful examples I know of are Velcro (1955) and the Anglepoise lamp. Velcro was invented by Georges de Mestral whose hairy dog pulled some of the hooked seeds from the seed heads of burdock as it ran past them. The hooks stuck in the dog's fur. This struck de Mestral as interesting and a useful method for joining, so after several years of experimentation he arrived at a practical system. The main problem he found was manufacture, a common sticking point in biomimetics. Nature's design is sophisticated and rarely lends itself to cheap, high-speed, manufacturing processes. There is a great variation of design available for joining in biological systems (figure 1). Some hooks, such as those on the seeds of the New Zealand weed piri-piri (Acaena sp.), hang on very strongly. Others, such as the small hooks on the stem of Galium spp., are little more than friction devices. The hooks upon which Velcro depends are made of stiff loops emerging from a textile that are cut at an angle to one side. However, that is only half the Velcro system. The hooks embed themselves into a pile of 'hairs' that are loops of monofilaments. These can break if they are too fine or badly manufactured, and the Velcro is then useless. As a product Velcro is very successful; there are approximately 1700 patents on its different uses.

\section{FLIGHT}

Another technology that has benefited from what happens in nature is flight. Clement Ader used the bat (Chiroptera) as the model for his flying machine, Eole (Coineau \& Kresling 1987). This machine is on display at the Musée de Paris. It was powered by an extremely light steam engine, and achieved a short flight in 1896. The whole structure of the wings is based on the morphology of the bat, even to their folding. The propellers also fold and are based on a feather design. Hardly 


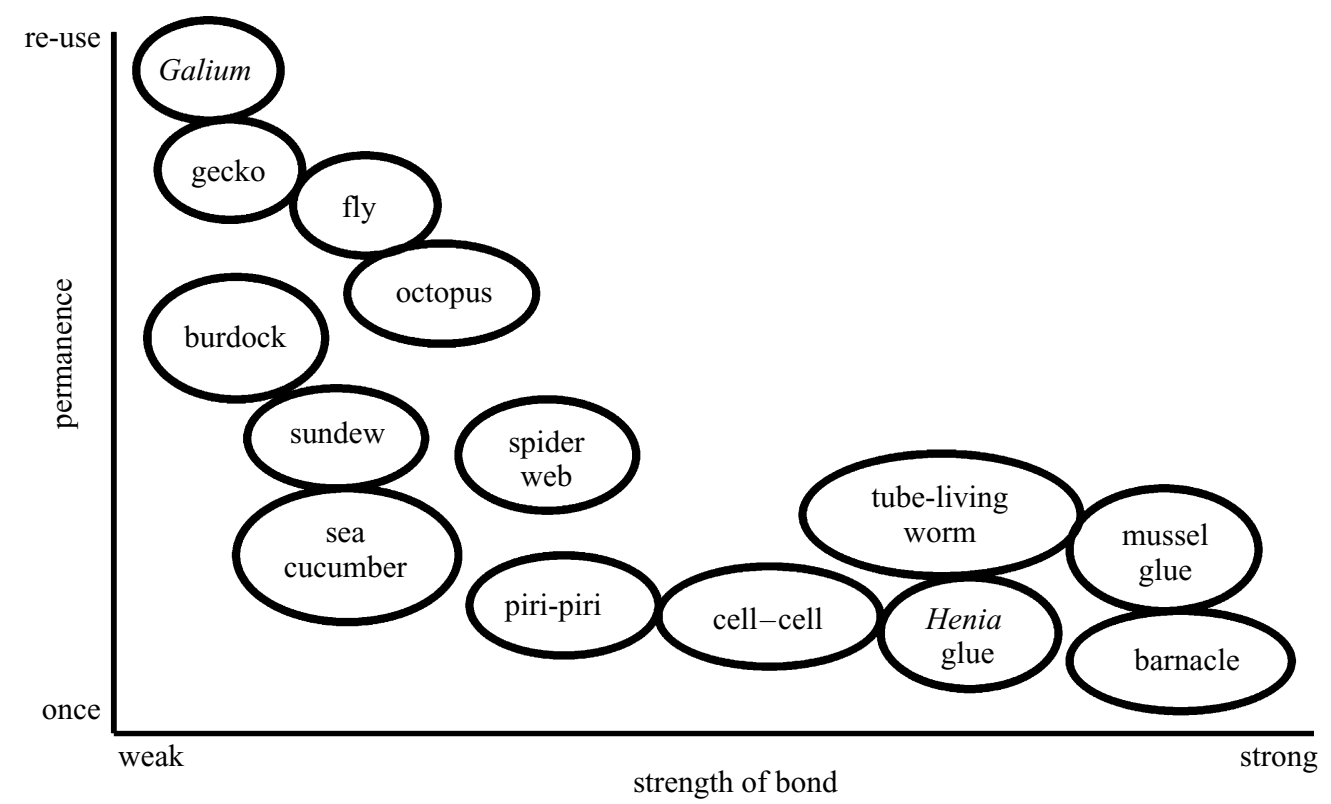

Figure 1. Strength of joint related to 'permanence' in biological systems. Galium (bedstraw, cleavers) climbs up hedges by using little more than differential friction. Henia is a centipede that glues the mouthparts of its assailant, making it harmless.

anything is gained by copying nature so closely. In most instances it is a mistake to do so because the optimizations of a natural structure are usually very different from the optimizations of a man-made structure. The successful flying machine owes little to nature because it is made from different materials and is far larger, necessitating fixed wings and a separate power plant.

\section{LOTUS EFFECT}

A much more recent, and apparently successful, biomimetic product is paint based on the water repellence of leaves, such as those of the lotus. Insect wings have a similar property. A drop of water placed on the leaf has a positive meniscus, indicating that it is not wetting the surface. The drop then not only runs off very easily, but also takes any foreign material such as particles and other liquids with it because they, too, do not adhere to the surface. This effect is achieved by many small hydrophobic tubercles on the surface layer (Barthlott \& Neinhuis 2000). The surface of the leaf is thus 'self-cleaning'. Several companies have developed paints based on this effect; these paints are now used for exterior work, keeping the walls of buildings free of adhering dirt. However, it still requires extensive testing. For example, how easily can bacteria stick to this surface, as they might do when the surface is exposed to the elements for extended periods? Bacteria are too small to respond in the same way as a water droplet and so may stick to the surface and colonize the hollows between the tubercles. In this way they could eventually cover the entire surface of the paint and destroy the self-cleaning behaviour. This prompts the questionhow does the lotus leaf (and other self-cleaning surfaces) avoid this effect? It only needs to last long enough for the leaf to die first, and the whole system will be self-regenerating. This would not be possible in the technological world where the surface must be regenerated either by more sophisticated cleaning or by repainting.

\section{EXPANSION OF LEAVES}

Expanding leaves have provided fodder for biomimetics. The original work (Kobayashi et al. 1998, 2000) was entirely driven by curiosity. The leaf form is generated by using the basic origami fold. This gives a very compact fold, but unfortunately all the fold lines fall on top of each other when the structure is folded. If one wanted to make a real deployable structure the 'fold lines' would have substantial thickness and could not be allowed to sit next to each other if the folded structure were to be compact. The aim is to produce the greatest ratio between folded and deployed area without making the folding/unfolding process too complex. These membranes are being developed for deployable camouflage coverings with the UK Ministry of Defence.

\section{SENSING IN FIBROUS COMPOSITES}

Recently we have been modelling the campaniform sensillum of insects (Skordos et al. 2002). These are holes in the cuticle of the insect that, because they are not round but oval, can be deformed more by strains in one direction than another. In the cockroach leg, two fields of sensilla with their long axes orthogonal to each other can detect intrinsic (proprioceptive) and extrinsic (extrareceptive) bending, compression, tension and twisting. The displacement of the hole is rotated through $90^{\circ}$ by the mechanism of a dome that stretches across the hole, which takes the direction of displacement out of the plane of the cuticle so that it can be detected by a sense cell situated in the cuticular epidermis. However, a hole introduces both compliance (which is what is needed here) and susceptibility to cracking (which is not needed). Generally holes are avoided by engineers and not regarded as an advantageous aspect of design. Insects design holes into their structure, but with remarkable care. For example, the fibrous component (chitin) is orientated around the sensillar holes and so tends to carry any loads around the hole; in a man-made fibrous composite holes would generally 


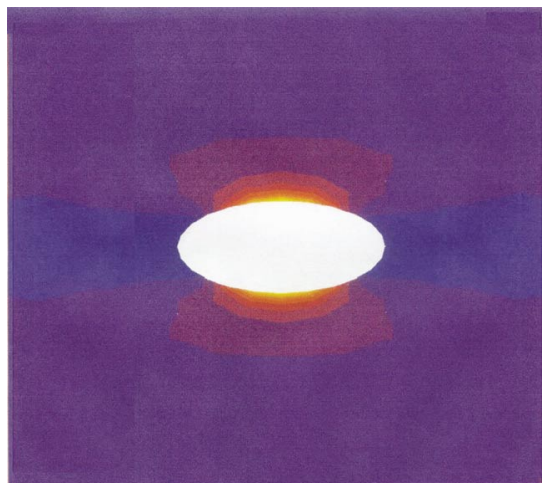

Figure 2. Finite elements model of a hole through a plate of GFRP. The fibres are arranged parallel horizontal, the hole cuts through the fibres, and the plate is stretched horizontally. Blue/purple is low stress, yellow is high, so the plate is in danger of breaking with a vertical fracture, initiated at the edge of the hole.

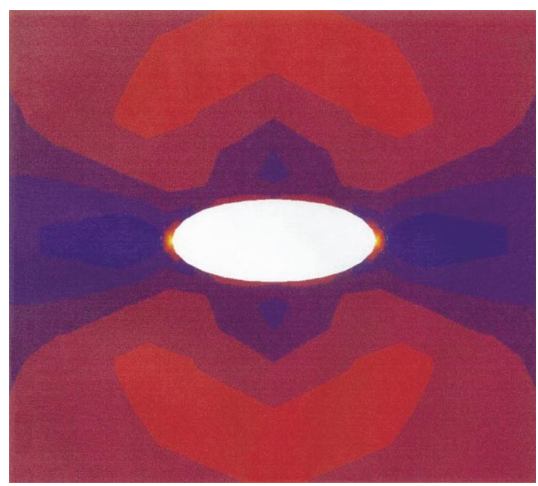

Figure 3. A plate like that shown in figure 2, except that the fibres are continuous around the hole, being deflected by it. It is stretched by the same amount. Stress is distributed much more evenly and the plate is not in danger of breaking. Also, the hole has deformed more, and so is a more sensitive indicator of global deformation.

be drilled and the load-carrying fibres interrupted. We used finite elements to model these two cases-formed and drilled oval holes - in a composite in which the fibres were orientated uniaxially. When the model was extended in the direction of the fibres, the drilled hole developed high stress concentrations on either side at the ends of the minor axis, where cracking would obviously start (figure 2 ). With a formed hole, however, the forces are taken around the hole by the fibres (figure 3 ). The distribution of strain is much more even across the specimen and the stress concentrations are smaller and at the ends of the major axis in line with the applied strain and thus perfectly safe. Additionally, the fibres going around the hole tend to compress it, further increasing the deformation induced by stretching (Skordos et al. 2002). A similar structure occurs in spiders (Barth 1978) where the slit sensilla (very long holes) can detect strain fields with great sensitivity.

\section{TOUGHNESS}

(a) Wood

Some 25 years ago Jim Gordon pointed out that the work of fracture of wood could not be adequately

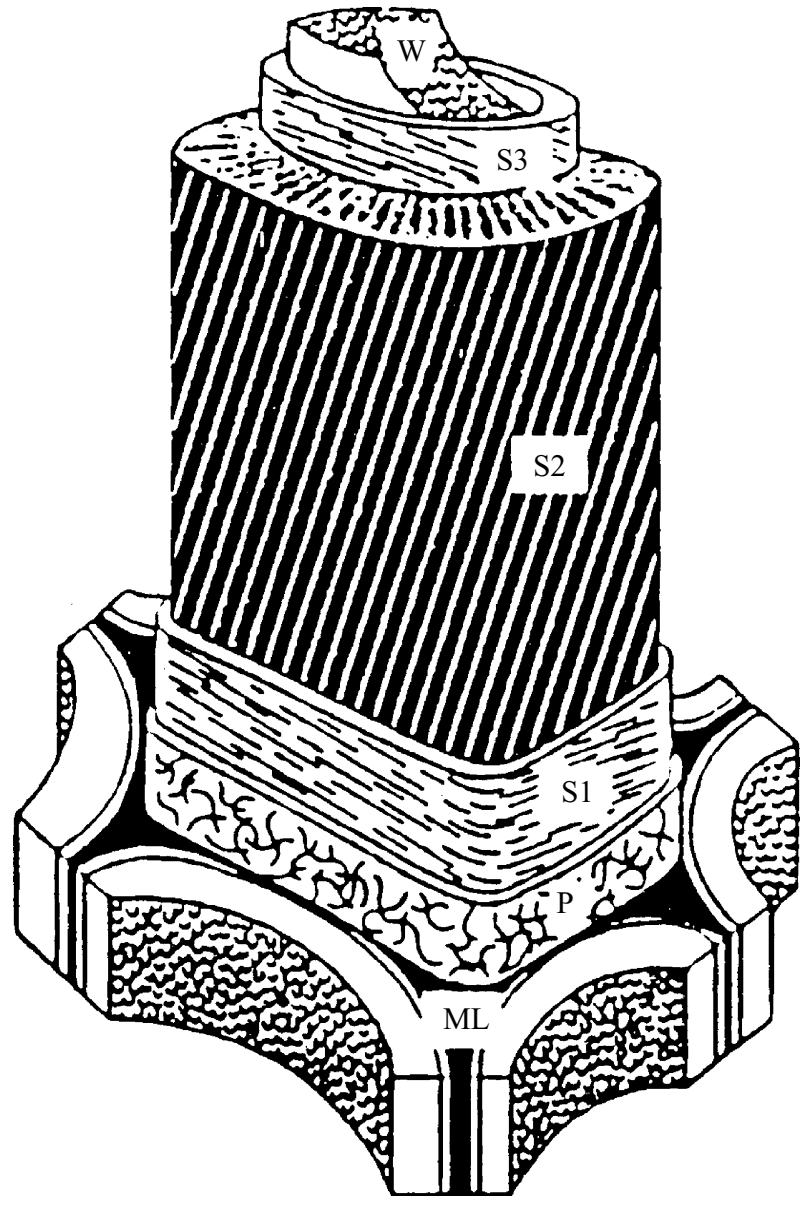

Figure 4. Typical softwood xylem cell showing the orientation of the cellulose microfibrils. The S2 layer represents $c a .80 \%$ of the total thickness. ML, middle lamella; P, pectin layer; S1-S3, cell layers; W, water inside the cell.

explained in terms of fibre pull-out, in which the friction between the cells as they were pulled apart when the wood was broken was supposedly adequate to account for the energy dissipated by the material. The secret lies in the morphology of the wood cells (figure 4 ) in which the S2 layer of the cell wall, which contributes $80 \%$ of the thickness, is composed of uniaxially orientated cellulose microfibres, orientated at $15^{\circ}$ to the long axis of the cell, embedded in a matrix of lignin. The microfibres in the remaining layers are functionally randomly orientated. This uniformity of structure in the S2 layer was common knowledge among botanists, but an engineering analysis showed that it was highly significant (Jeronimidis 1976). When a piece of softwood composed of cells with this morphology is stretched along the axis of the cells, the lignin fractures between the cellulose microfibres, thus allowing the cell to elongate, become narrower, and pull itself away from the surrounding cells (figure 5). These two mechanisms not only generate a large amount of surface area that thus dissipates large amounts of energy, but they also allow the cellulose microfibres to continue carrying a tensile load across the failure zone. A tube made from glass fibres wound at $15^{\circ}$, embedded with resin, and then stretched, gives a typical force deflection curve (figure 6) in which the initial failure is due to the resin between the fibres failing in shear (Gordon \& Jeronimidis 


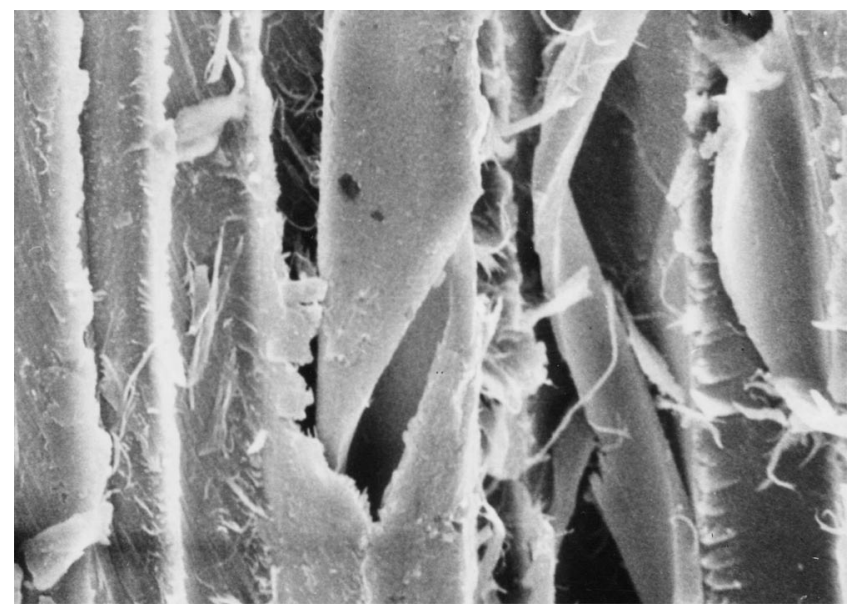

Figure 5. Spruce wood broken in tension (vertical direction). The matrix between the cellulose fibres in the cell wall has fractured in a helical fashion leaving the cellulose microfibres intact, hence still capable of carrying a load.

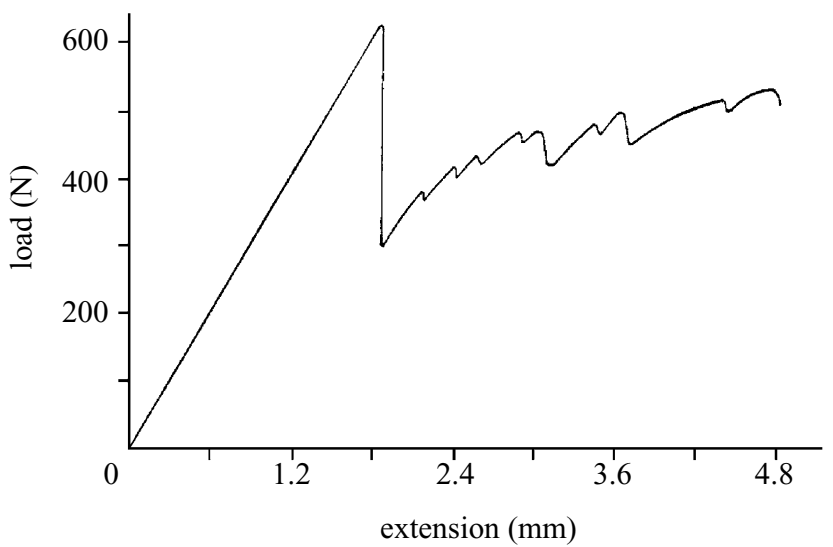

Figure 6. Failure curve of a tube of GFRP wound at $15^{\circ}$. After the initial failure, many small ones follow in a more or less controlled manner, thus extending the strain to failure and absorbing large amounts of energy (proportional to the area beneath the curve).

1980). The tube continues to carry a load because the fibres themselves do not break as readily; rather, they rotate towards the long axis of the fibre, shearing the matrix more in doing so and giving rise to further failures. One by one they break, of course, but the force deflection curve encloses a large area showing that the tube has dissipated a large amount of energy. The overall shape of the curve is not unlike that for a ductile metal breaking, showing that nature not only does not need a metallic tradition to make durable ductile structures, but can also produce the effect using brittle materials-cellulose and lignin! This mechanism can be incorporated into models of wood made either from individual wound tubes stuck together or from sheets of uniaxially orientated fibres in plastic, corrugated and assembled with the fibres running at an angle to the corrugations (figure 7; Chaplin et al. 1983). When the models are assembled from individual tubes, the surface generated when a sample is fractured shows 'splinters' much like a piece of broken wood (figure 8), and the maximum energy absorption occurs when the tubes are wound at an angle of $15^{\circ}$ (figure 9; Gordon \& Jeronimidis 1980). The fibres in the tree are therefore

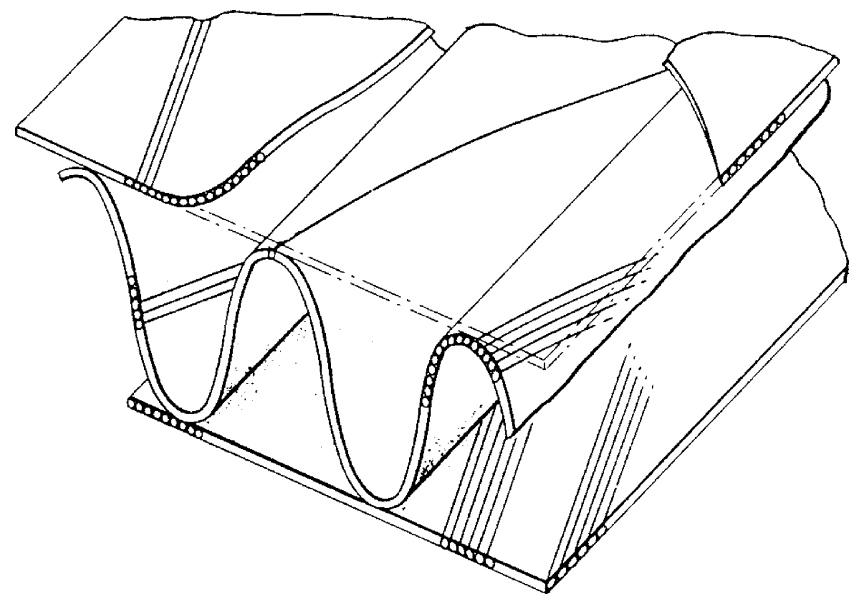

Figure 7. Another way of making a system of tubes with angled fibres. This uses corrugation, with the fibre angle alternating between $+7^{\circ}$ and $-7^{\circ}$.

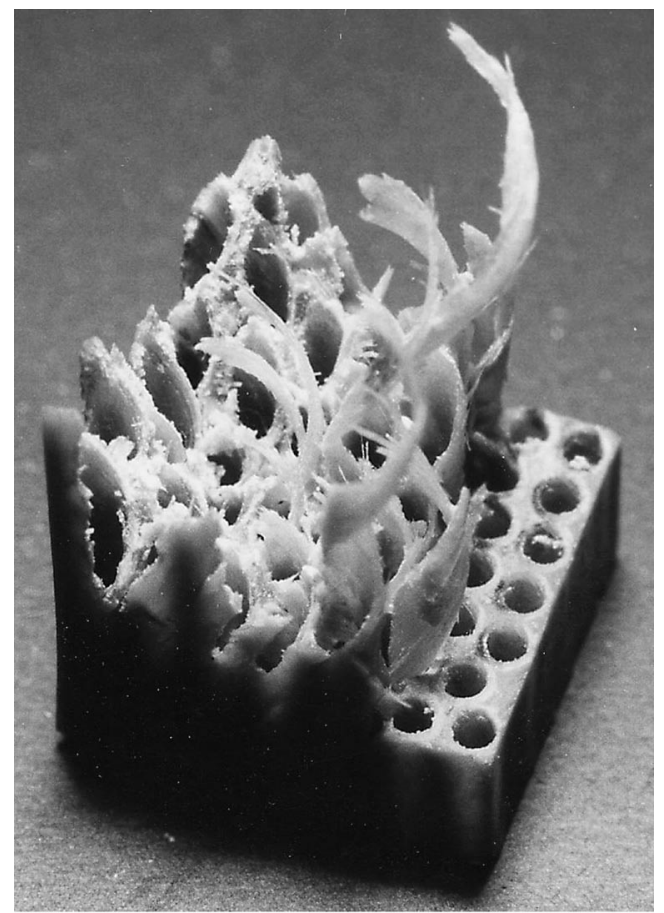

Figure 8. A wood model made of several wound GFRP tubes; the fracture surface is very similar to splintered wood, although the tubes are $c a .1 .5 \mathrm{~mm}$ in diameterapproximately 30 times the size of a wood cell.

wound for maximum toughness. This general observation-that off-axis microfibres can generate a pseudoductility-has also been observed in hemp fibres. Plates made in this way can have nails hammered into them without splitting, showing the high damage tolerance of wood. This is because of the angles at which the fibres are arranged and the presence of holes, which allow the fibres to move out of the way of the nails rather than break, and which then hold the nails in place by friction. This material will stop bullets and form a very effective shield against attack by a knife, tending not just to resist the knife but also to hold it, thus depriving the attacker of his/her weapon. Why is such a material not available commercially - which it should be, of course, because it outperforms nearly every other form of body armour material by 


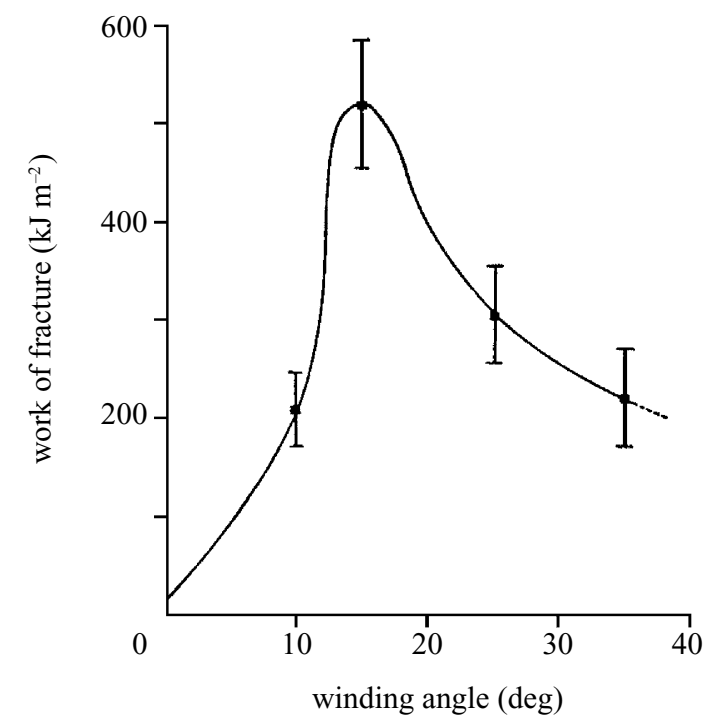

Figure 9. Work of fracture varies with the winding angle in the GFRP tubes. At $15^{\circ}$ (the same as in the tree cells) it is at a maximum.

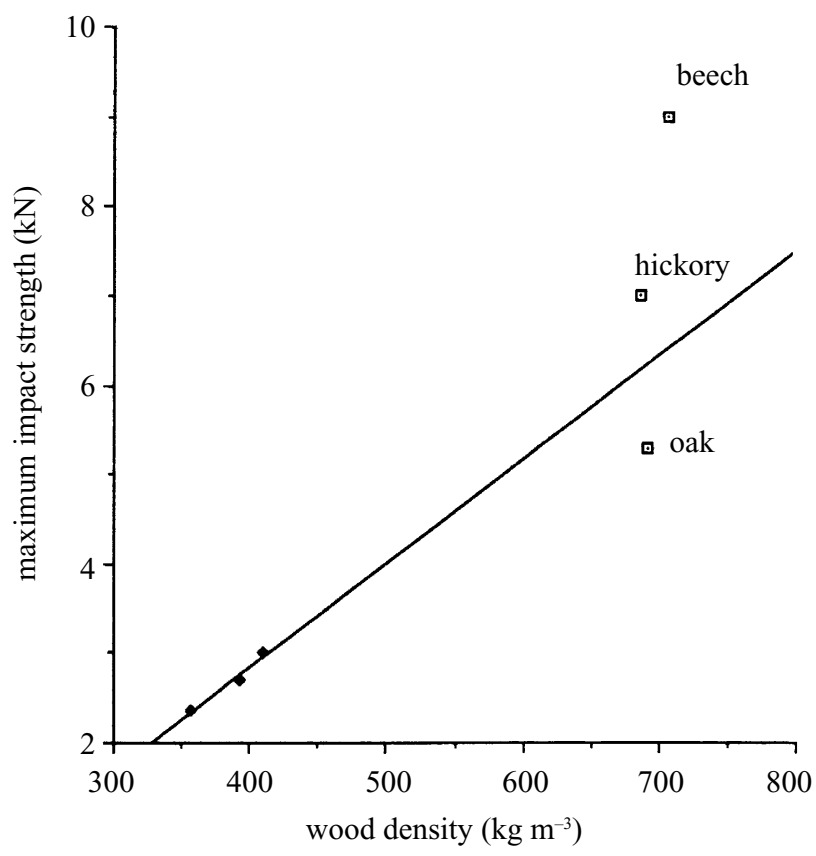

Figure 10. Impact strength of spruce (filled diamonds to left of graph) is proportional to density; that of three hardwoods (right) is not. The presence of many large cells in the hardwood distributes the collapse of the material, hence the absorption of energy, over a greater volume of the material.

a factor of $50 \%$ ? This is where biomimetics becomes more difficult, because there are problems in commercializing some of these ideas. It is all very well for scientistsbiologists - to say that we can generate useful concepts, but industry has to accept those ideas. A second problem with the wood analogues is that at present we can produce it only in flat plates, which severely limits its usefulness. There is a need for design input that can come only from the engineering side.

Wood is further toughened by the presence of holes of different sizes (Hepworth et al. 2002). In impact orthogonal to the long axis of the grain, the energy absorption

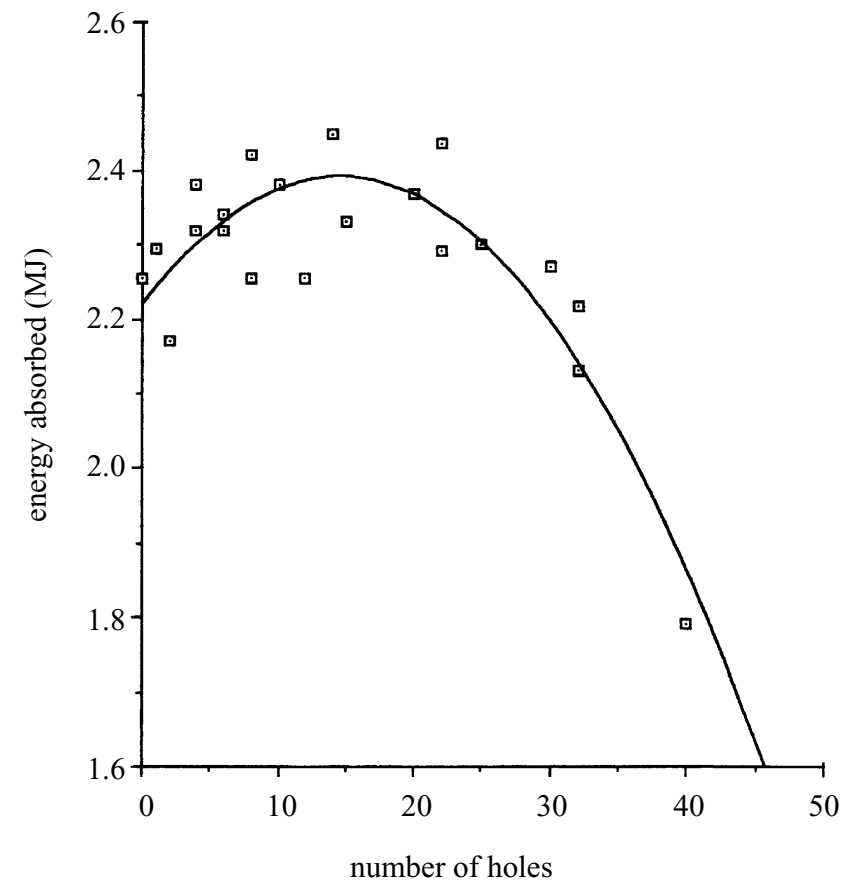

Figure 11. Effect of drilling holes $0.6 \mathrm{~mm}$ diameter into blocks of spruce, in which all the wood cells are ca. $0.05 \mathrm{~mm}$ diameter. This distributes the collapse of the material more uniformly, in imitation of the effect of tracheids in hardwood.

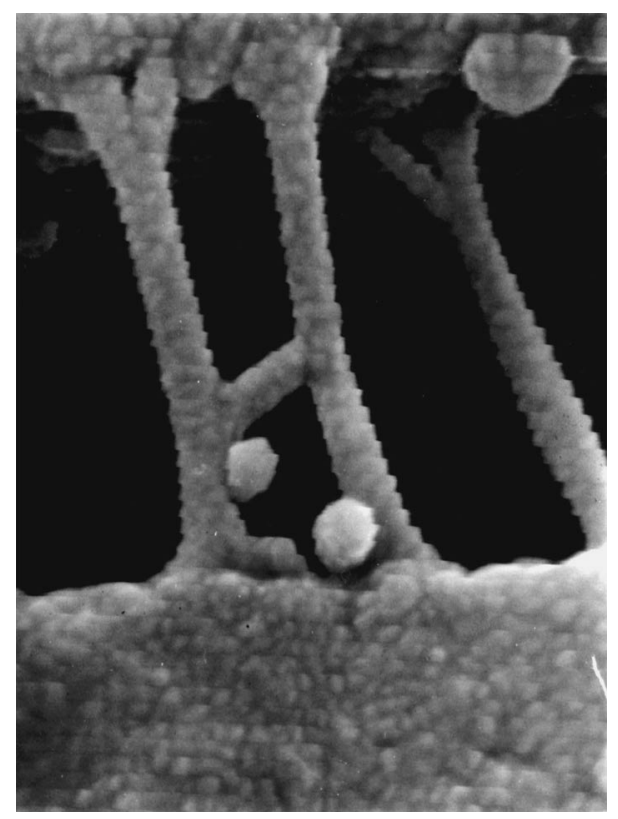

Figure 12. Strand of matrix protein pulled out between the plates of nacre when it fractures.

of softwoods (which are composed of tubes mostly ca. $50 \mu \mathrm{m}$ in diameter) is proportional to their density, but the energy absorption of hardwoods cannot be so easily explained (figure 10). It transpires that this is due to the arrangement of the water-conducting vessels (tubes of diameter $500 \mu \mathrm{m}$ ) found only in hardwoods. Oak, which absorbs relatively little energy, is ring-porous: the vessels occur in discrete rings or rows. Hickory and beech, both good absorbers of impact energy, are diffuse-porous with the vessels more evenly distributed throughout the wood. Each of the vessels acts as a focus for damage so that in 


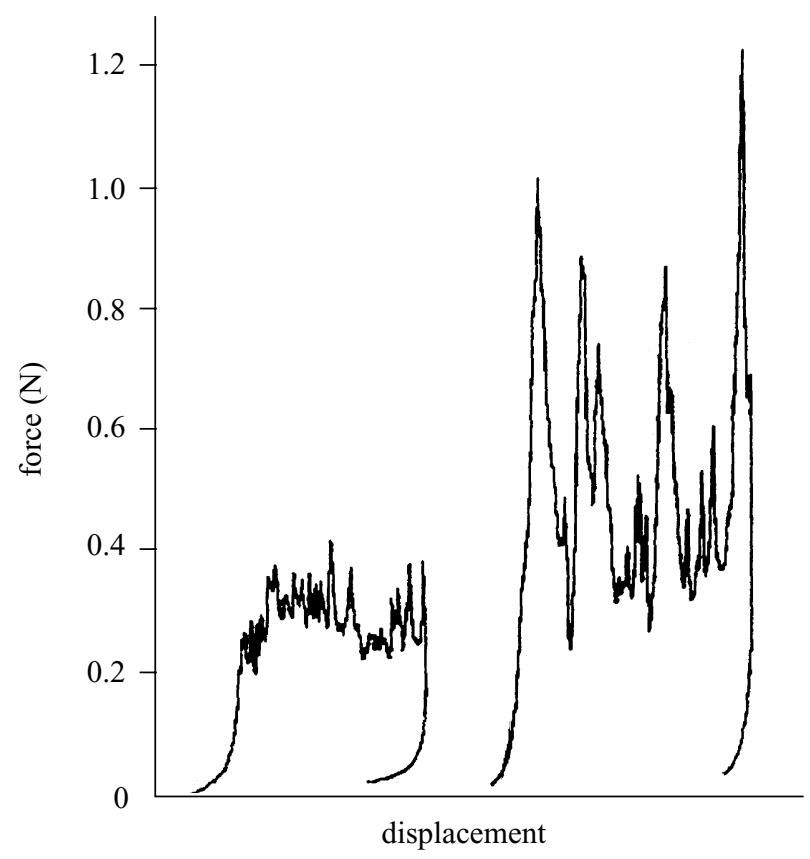

Figure 13. Increase of tear strength of tracing paper. Left: before modification; right: after putting four rows of elongated holes in the paper edge and filling them with Araldite. Displacement is $c a .10 \mathrm{~mm}$ for each sample (i.e. the width of the slotted zone).

diffuse-porous wood all the cells can contribute to the absorption of fracture energy. This can, of course, be mimicked by drilling holes in pine, thus producing the texture of a hardwood. The result is as expected-an increase in energy absorption (figure 11).

\section{(b) Nacre}

Mother-of-pearl is another interesting material. It is $95 \% \mathrm{CaCO}_{3}$, made of platelets ca. $0.5 \mu \mathrm{m}$ thick. In fracture, the generation of a stepped fracture surface with platelet pullout accounts for $c a .50 \%$ of the total available work of fracture. Clegg has used this mechanism to develop a sandwich structure made of sheets of siliconbased ceramic, ca. $20 \mu \mathrm{m}$ thick, separated by layers of carbon powder. When sintered at $c a .1000{ }^{\circ} \mathrm{C}$ this results in a very tough material which is being developed for uses such as the combustion chamber of jet engines. This material has a work of fracture in bending of $c a .4 .5 \mathrm{~kJ} \mathrm{~m}^{-2}$ compared with the $1.2-1.5 \mathrm{~kJ} \mathrm{~m}^{-2}$ of mother-of-pearl (Jackson et al. 1988). However, this is using only one of the toughening mechanisms available in mother-of-pearl. The other toughening mechanism is due to the generation of filaments between the platelets as they are pulled apart (figure 12). These filaments are probably silk-like and account for the remaining $50 \%$ of energy absorption. This mechanism is being investigated for the manufacture of toughened glassy materials, which can resist water droplets travelling faster than sound, which represent a hazard for a fighter aircraft flying through rain. Water droplets sprayed at supersonic speeds at a Haliotis shell do little more than remove a few layers of the mother-of-pearl, whereas glass is immediately shattered.

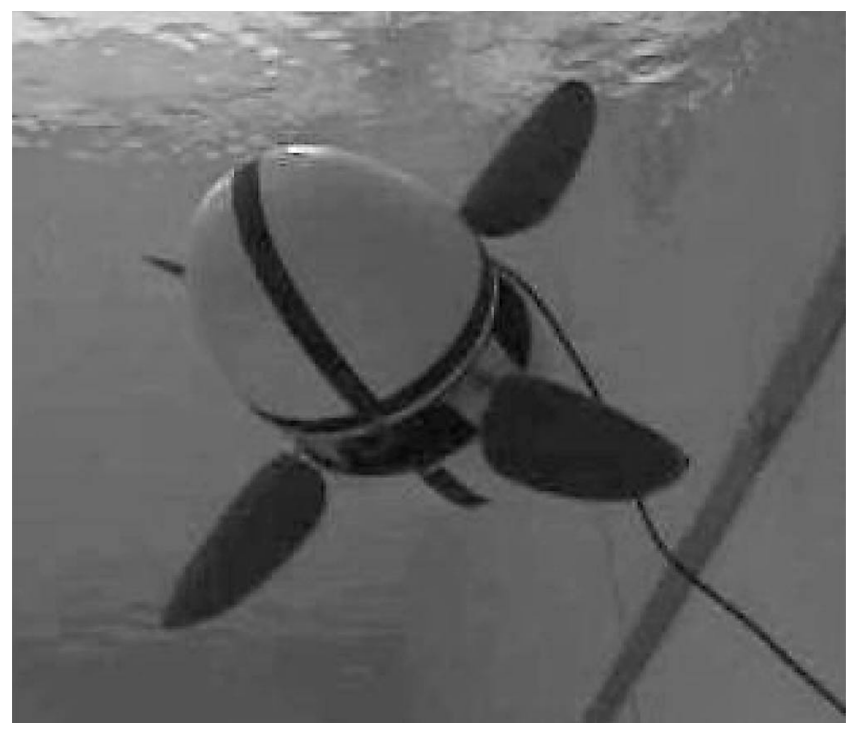

Figure 14. The PilotFish, powered by four actuators that are modelled on a fish. PilotFish image copyright 2002 Nekton Research, LLC (used with permission).

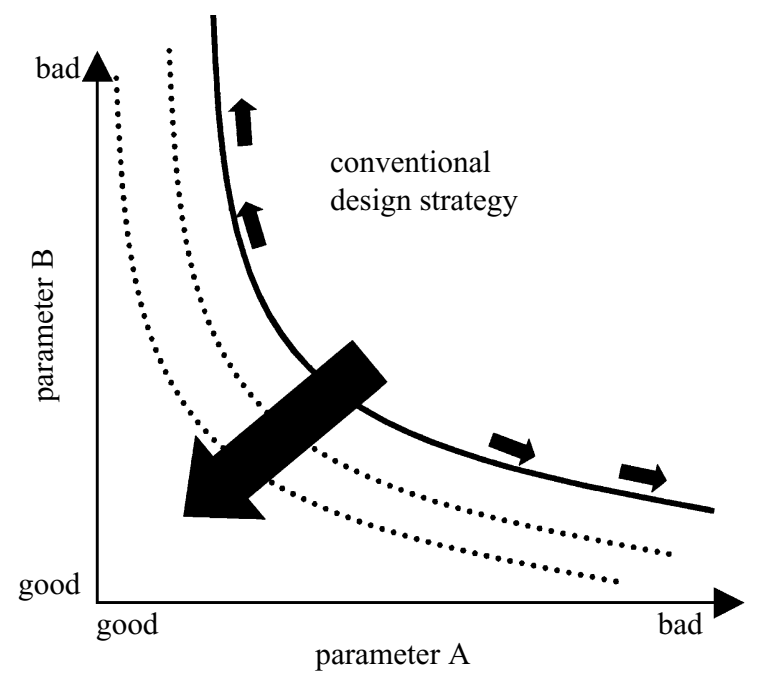

Figure 15. Engineers are taught to optimize and compromise: improvement in parameter A necessarily results in downgrading parameter B. TRIZ can suggest new design solutions based on identifying the conflict between the two parameters of the compromisation, showing how the compromise can be broken. Hence both parameters can be improved at the same time (heavy arrow).

\section{(c) Paper}

A similar approach - the introduction of deformable layers in a brittle material - has been used to resist edgedamage in tracing paper. Tracing paper is still the preferred material for drawing by architects, but it suffers damage at the edge, which can initiate a tear across the sheet. The normal way to resist this is to tape over the damage, but this increases the thickness of the paper and does not necessarily increase resistance to further tearing. The remit was to toughen the edge of the paper against tearing without increasing its thickness. A trouser-tear test (imposing outof-plane shear-mode III fracture) of the untreated paper gave a force of $c a .0 .3 \mathrm{~N}$ to tear paper of $63 \mathrm{~g} \mathrm{~m}^{-2}$. I took the idea of making the crack go through individual layers from the way mother-of-pearl fractures, leaving me with a 
mechanism rather like that proposed by Cook \& Gordon (1964). This was achieved by making five rows of elongated holes, staggered from row to row parallel to the edge of the paper, and filling them with resin. This occupied $c a .1 \mathrm{~cm}$ all the way round the paper. As a crack progresses through the paper at the edge it is deflected by the resin-filled holes which not only requires a higher force for propagation, but the crack also has to be restarted on the other side of the hole (figure 13). This increased the force to $c a .1 \mathrm{~N}$.

\section{(d) Technology transfer}

The 'TwiddleFish', which was invented by Chuck Pell and Steve Wainwright as a child's toy, has been used by the company Nekton to propel 'PilotFish', a highly manoeuvrable midget submersible whose development was funded by the Defence Advanced Projects Research Agency of the USA. It has six degrees of freedom in its movement, using four impellers based on the TwiddleFish mechanism (figure 14). In this instance the concept was transferred from nature by two people who are skilled in the art of application of ideas. In general, however, the transfer of ideas from biology into technology is random and adventitious. We need to establish a way in which engineers can access ideas from the world of nature without the need of a biologist to do the interpretation. Put more generally, we need to formalize the process of innovation and the solution of problems by inventing a process by means of which we can access concepts from a different problem-solving area. The answer, I think, lies in the Russian Theory of Inventive Problem Solving, TRIZ (Altshuller 1999), which was designed to do just this, but within an engineering environment only. TRIZ takes design away from the trap of optimization, in which one parameter can be improved only at the expense of another, and shows how both parameters can be simultaneously improved in a design problem - the much-sought-after 'win-win' situation (figure 15). It does this by helping to identify the reason why improvement is impossible, expressing this as a contradiction. For example, if you want to make something stronger, you usually have to make it heavier, which in many cases may not be possible within the design limitations. If, however, you understand something of fracture mechanics and, more specifically, if you know some of the methods that natural systems have evolved to increase toughness, you may realize that holes, carefully used, can improve strength while at the same time actually making the structure lighter. TRIZ will reveal this solution once you have defined the problem in its terms. There are only 40 inventive principles to provide this solution, the result of distilling over 3000000 of the most innovative and successful patents. TRIZ has other tools, showing how technology (and nature) evolves, thus allowing one to leapfrog the normal pathway of development of a concept. Still other tools itemize the ways available for the solution of a problem, and the objective statement of the problem. We are currently expanding the TRIZ system to use biological solutions, and will make the results freely available at a later date.

\section{CONCLUSIONS}

Although ideas from biology have been used for the inspiration of engineers for upwards of 2000 years, the methods used successfully to introduce biological concepts into technology have been adventitious to say the least. With our better understanding of biology and of mechanisms for innovation (in particular, TRIZ) we have reached a stage when the systematic transfer of concepts from biology - biomimetics-could be a consistent and productive way of improving our technology.

\section{REFERENCES}

Altshuller, G. 1999 The innovation algorithm, TRIZ, systematic innovation and technical creativity. Worcester, MA: Technical Innovation Center Inc.

Barth, F. G. 1978 Slit sense organs: 'strain gauges' in the arachnid exoskeleton. Symp. Zool. Soc. Lond. 42, 439-448.

Barthlott, W. \& Neinhuis, C. 2000 The lotus effect. See http://www.botanik.uni-bonn.de/system/bionics.htm.

Chaplin, R. C., Gordon, J. E. \& Jeronimidis, G. 1983 Development of a novel fibrous composite material. Patent no. 4409274

Coineau, Y. \& Kresling, B. 1987 Les inventions de la nature et la bionique. Paris: Museum National d'Histoire Naturelle.

Cook, J. \& Gordon, J. E. 1964 A mechanism for the control of crack propagation in all-brittle systems. Proc. R. Soc. Lond. A 282, 508-520.

Gordon, J. E. \& Jeronimidis, G. 1980 Composites with high work of fracture. Phil. Trans. R. Soc. Lond. A 294, 545-550.

Hepworth, D. G., Vincent, J. F. V., Stringer, G. \& Jeronimidis, G. 2002 Variations in the morphology of wood structure can explain why hardwood species of similar density have very different resistances to impact and compressive loading. Phil. Trans. R. Soc. Lond. A 360, 255-272. (DOI 10.1098/rsta. 2001.0927.)

Jackson, A. P., Vincent, J. F. V. \& Turner, R. M. 1988 The mechanical design of nacre. Proc. R. Soc. Lond. B 234, 415-440.

Jeronimidis, G. 1976 The work of fracture of wood in relation to its structure. In Wood structure in biological and technological research, Leiden Botanical series 3 (ed. P. Baas, A. J. Bolton \& D. M. Catling), pp. 253-265. Leiden: University Press.

Kobayashi, H., Kresling, B. \& Vincent, J. F. V. 1998 The geometry of unfolding tree leaves. Proc. R. Soc. Lond. B 265, 147-154. (DOI 10.1098/rspb.1998.0276.)

Kobayashi, H., Daimaruya, M. \& Vincent, J. F. V. 2000 Folding/unfolding manner of tree leaves as a deployable structure. In Deployable structures: theory and applications, Proc. IUTAM Symp. 1998 (ed. S. Pellegrino \& S. D. Guest), pp. 211-220. London: Kluwer.

Skordos, A., Chan, P. H., Vincent, J. F. V. \& Jeronimidis, G. 2002 A novel strain sensor based on the campaniform sensillum of insects. Phil. Trans. R. Soc. Lond. A 360, 239-253. (DOI 10.1098/rsta.2001.0929.)

Velcro, S. A. 1955 Improvements in or relating to a method and a device for producing a velvet type fabric. HMSO Patent Office no. 721338 .

Vincent, J. F. V. 2002 Survival of the cheapest. Mater. Today 5, December 28-41.

\section{GLOSSARY}

GFRP: glass-fibre reinforced plastic 